\title{
Clinical and Metabolic Study in Diabetic Patients Treated with Glibenclamide
}

\author{
J. ANDERSON,* M.D., в.SC., F.R.C.P. ; R. COULSON, $†$ B.SC., PH.D. ; B. D. M. GRASSICK, $\ddagger$ м.B., Сн.в. \\ B. A. MORRIS, † B.SC., A.R.I.C. ; W. D. THOMAS, † B.SC. ; R. W. S. TOMLINSON, $§$ B.SC., PH.D. \\ F. WOODROFFE, $\|$ M.B., M.R.C.P.
}

British Medical fournal, 1970, 2, 568-570

\begin{abstract}
Summary: A clinical and metabolic study of 32 patients treated with glibenclamide for a period of about one year confirmed that the drug is a potent stimulator of insulin release in maturity onset diabetes, and glibenclamide continued to have this action after a period of eight months. The drug is effective in doses as low as $2.5 \mathrm{mg}$., and the maximum effective dose is about $15 \mathrm{mg}$. No significant side-effects were found during the period of the study, in particular there was no alcohol flushing. The metabolic investigations have shown that the drug has some actions which are as yet unexplained.
\end{abstract}

\section{Introduction}

Glibenclamide (HB 419, Daonil), a hypoglycaemic sulphonylurea (Aumüller et al., 1966), has been used successfully for the management of patients suffering from maturity onset diabetes (Müller et al., 1969). In the present investigation the effects of glibenclamide were studied over one year in 32 diabetic patients.

\section{Patients and Methods}

Nine men and 23 women aged 40-83 (mean 60) years who had suffered from diabetes for 1 to 16 years were studied. Twenty-eight were responding poorly to treatment with either diet or diet and oral hypoglycaemic drugs and four were on insulin but not prone to ketosis. Their diet was kept constant throughout the study. Those who had been treated with other sulphonylurea drugs started treatment with $5 \mathrm{mg}$. of glibenclamide at breakfast-time daily, but those who had previously had treatment with diet alone started with $2.5 \mathrm{mg}$. As experience was gained treatment began with $5 \mathrm{mg}$. in all cases. Patients were seen monthly and dosage was adjusted on the basis of the blood glucose two hours after breakfast and degree of glycosuria. The dose of glibenclamide given ranged from 2.5 to $35 \mathrm{mg}$. daily.

The investigations were chosen to determine if there was any change in clinical diabetic control, to measure the response to a standard $50 \mathrm{~g}$. oral glucose tolerance test, to detect any effect on blood or liver function, and to determine the changes in other metabolic intermediates related to diabetes mellitus. Glucose tolerance tests were carried out before the start of treatment with glibenclamide and when there was no further clinical improvement in diabetic control by increasing dosage of the drug. When the glucose tolerance test was carried out blood was also taken for the other metabolic investigations. At each monthly visit the patient was weighed before clinical examination and careful inquiry was made

\footnotetext{
* Professor of Medicine.

$\dagger$ Research Fellow.

$\ddagger$ Honorary Lecturer.

Senior Lecturer.

if Lecturer.

Department of Medicine, King's College Hospital Medical School, London S.E.5.
}

for side-effects attributable to the drug, particularly hypoglycaemic symptoms and alcohol flushing. Venous blood samples were taken at these visits for haematological and liver function tests.

Blood glucose concentration was measured by the method of Hugget and Nixon (1957), plasma insulin by a modified method $\mathrm{C}$ of the double antibody immunoassay of Hales and Randle (1963), and plasma non-esterified fatty acids by the method of Dole (1956). Plasma cholesterol was measured colorimetrically and blood lactate, pyruvate, acetoacetate, serum lactic dehydrogenase, serum aspartate and alanine aminotransferase activities (S.G.O.T. and S.G.P.T. respectively) were assayed enzymatically, with standard kits supplied by Boehringer and Soehne. Haemoglobin, white cell and differential counts, platelet counts, bilirubin estimations, serum protein concentration, and electrophoresis were carried out in the hospital laboratory by the standard methods.

\section{Results}

The degree of clinical control (assessed by a blood glucose concentration two hours after breakfast) before and after 6 and 12 months on glibenclamide is shown in Table $I$, the criteria of Müller et al. (1969) being used in the assessment.

TABLE I.-Degree of Clinical Control Before Starting Glibenclamide and 6 Months and 1 Year After Treatment

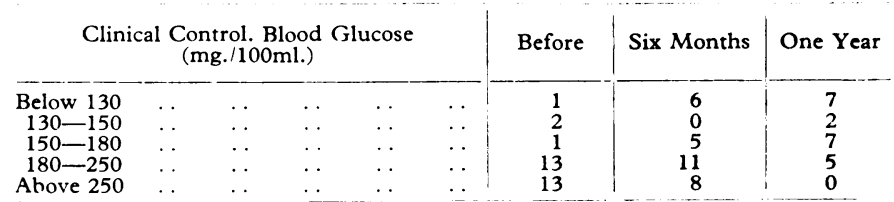

The 32 patients chosen for this study presented difficulties in the control of their diabetes. Four were transferred from insulin treatment and two of these were not well controlled over the period of study. When given a biguanide in addition during the last three months there was still no improvement. Five of the patients who before this study were on a biguanide and a high dose of a sulphonylurea were given a biguanide in addition to glibenclamide in the last three months of the study with some additional improvement in diabetic control. Two of the 32 patients who entered the study were withdrawn before six months' treatment; one required treatment with insulin, the other had hypoglycaemic symptoms (though low blood glucose levels were not found).

Thirteen patients had a blood glucose concentration greater than $250 \mathrm{mg} . / 100 \mathrm{ml}$. at the start of the study and this number had fallen to eight at six months (Table I). There was only one patient at the beginning of the study whose blood glucose concentration was below $130 \mathrm{mg} . / 100 \mathrm{ml}$., representing excellent control, but at the end of the sixmonth period six patients fell into this category and at one year there were seven such patients. 
Glucose tolerance test results (Table II) also show a difference between the initial test before treatment and that after about eight months. The initial and final glucose tolerance test results for all patients are shown in Fig. 1. The improvement seen in those in whom control had failed with diet alone was greater than in those in whom control had failed with diet and another sulphonylurea drug.

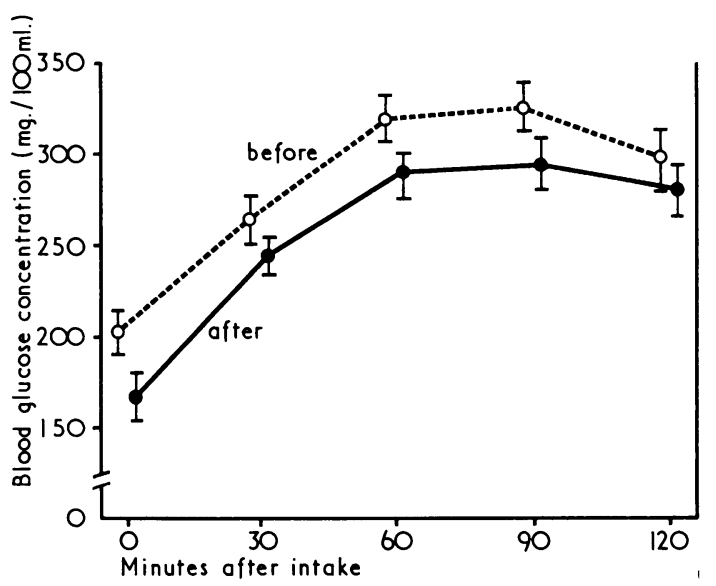

FIG. 1-Glucose tolerance tests before and after glibenclamide therapy-all patients.

Plasma insulin concentrations determined at the same time as the glucose tolerance test was carried out are shown in Table II and Fig. 2. Five patients had a glucose tolerance test and plasma insulin determination after the trial following a period of 13 to 16 months on the drug. There was no significant difference at this time in the glucose tolerance or in the plasma insulin concentration in this small group when compared with the initial test.

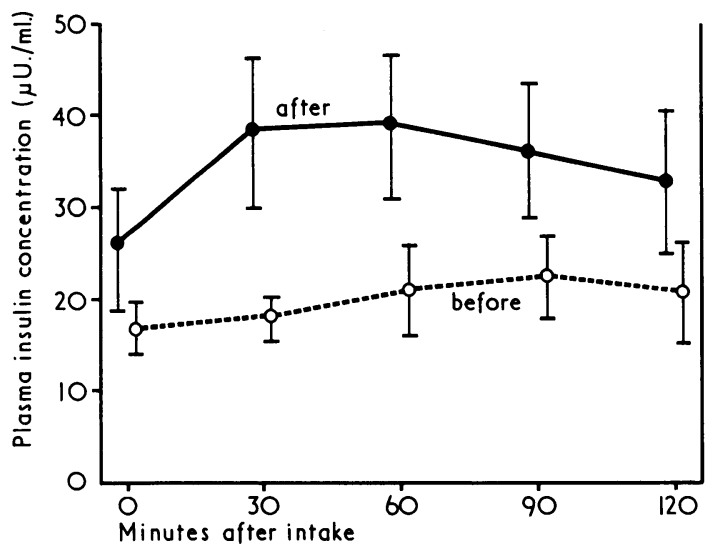

FIG 2.-Plasma insulin response to oral glucose in patients previously on diet and another sulphonylurea.
Other biochemical criteria.-The results of the other biochemical criteria studied at the time of the glucose tolerance tests are also shown in Table II. The significant changes were in the plasma cholesterol concentration, which decreased, as did the activity of lactic dehydrogenase, in the group as a whole, and in the non-esterified fatty acids and the blood pyruvate concentration, both of which increased. The results of the smaller group at about eight months on treatment show differences, but these were not significant.

The drug was well tolerated and, apart from one patient with hypoglycaemic symptoms, no side-effects were detected, even on maximum dosage when seven tablets $(35 \mathrm{mg}$.) were taken each morning as a single dose. In particular no patient admitted to flushing after taking alcohol, whereas Fitzgerald et al. (1962) found this complication in about one-third of the patients on chlorpropamide who took alcohol. The haemoglobin concentration, white cell count, and differential count remained within the normal range during the period of study. The platelet count showed transient falls in 10 patients but returned to normal within a month. In one of these patients the fall in platelets occurred before treatment with glibenclamide was started and her count returned to normal during the first month on the drug.

The serum bilirubin and serum protein concentrations, the S.G.O.T. and S.G.P.T. activities remained within the normal range throughout the study. There was no significant change in the weight of the patients during the period of the study.

\section{Discussion}

This study of glibenclamide confirms the earlier work summarized by Müller et al. (1969), which also shows it to be a potent oral hypoglycaemic agent. It is well tolerated, effective in once-daily dosage, and free from side-effects over a study period of one year. The clinical control as assessed by blood and urinary glucose concentrations gave as good an indication of the usefulness of glibenclamide as any of the other measurements taken. By these criteria the drug is effective in controlling the diabetic process reasonably well in over half the patients studied.

Another measure of the carbohydrate disturbance in diabetes is the glucose tolerance test, which is essentially an acute stress test. The overall glucose tolerance improved significantly during the study. The response of the oral glucose tolerance test to treatment with glibenclamide, however, does not appear to be related to clinical improvement as has already been shown for other sulphonylurea drugs (Duncan and Baird, 1960).

Seltzer et al. (1967) described the phenomenon of delayed initial response in insulin release to a glucose load in patients with "mild" diabetes. The initial insulin response in our patients on diet and those on diet plus a sulphonylurea was poor in both groups as well as in the group as a whole. The results when tested at eight months show a significant

TABLE II.-Summary of Results of Metabolic Investigations Before and After Treatment with Varying Doses of Glibenclamide, Showing Means \pm S.E. of Means, Significance of Differences Determined by "Paired t Test"

\begin{tabular}{|c|c|c|c|c|c|c|c|c|c|c|}
\hline & $\begin{array}{c}\text { Glucose } \\
\text { Tolerance } \\
\text { Test (area } \\
\text { under curve) } \\
\text { Min. } \\
\text { (mg./100 ml.) }\end{array}$ & $\begin{array}{c}\text { Insulin } \\
\text { Output } \\
\text { During } \\
\text { G.T.T. } \\
\text { (area under } \\
\text { curve) } \\
\text { Min. } \\
(\mu \mathrm{U} . / \mathrm{ml} .)\end{array}$ & $\begin{array}{c}\text { Plasma } \\
\text { Choles- } \\
\text { terol } \\
\text { (mg.! } \\
\text { 100ml.) }\end{array}$ & $\begin{array}{c}\text { Plasma } \\
\text { Non-esteri- } \\
\text { fied Fatty } \\
\text { Acids } \\
(\mathrm{mEq} / 1 .)\end{array}$ & $\begin{array}{c}\text { Blood } \\
\text { Aceto- } \\
\text { acetate } \\
(\mu \mathrm{g} . / \mathrm{ml} .)\end{array}$ & $\begin{array}{c}\text { Blood } \\
\text { Pyruvate } \\
(\mu \mathrm{g} . / \mathrm{ml} .)\end{array}$ & $\begin{array}{c}\text { Blood } \\
\text { Lactate } \\
(\mu \mathrm{g} . / \mathrm{ml} .)\end{array}$ & $\begin{array}{c}\text { Serum } \\
\text { Lactic } \\
\text { Dehydro- } \\
\text { genase } \\
\text { (mU./ml.) }\end{array}$ & $\begin{array}{l}\text { Serum } \\
\text { G.O.T. } \\
\text { (mU./mi.) }\end{array}$ & $\underset{\text { (mi.P.T }}{\text { Serum }}$ \\
\hline No. of patients analysed & 20 & 11 & 28 & 28 & 28 & 28 & 28 & 27 & 27 & 27 \\
\hline Before glibenclamide .. & $35,403 \pm 6,606$ & $2,797 \pm 435$ & $268 \cdot 1 \pm 11 \cdot 2$ & $982 \cdot 5+61 \cdot 8$ & $3.49 \pm 0.85$ & $5 \cdot 65+0.36$ & $8 \cdot 23 \pm 0.50$ & $160 \cdot 2+9 \cdot 0$ & $9.51+0.94$ & $7 \cdot 83 \pm 0.91$ \\
\hline After glibenclamide & $31,697 \pm 6,666$ & $6,019+839$ & $234 \cdot 5 \div 9 \cdot 3$ & $1196.9 \pm 79.6$ & $2 \cdot 72 \pm 0.37$ & $7 \cdot 25 \pm 0.69$ & $10 \cdot 67 \pm 1 \cdot 26$ & $132 \cdot 9 \pm 8 \cdot 4$ & $7 \cdot 96+1.25$ & $7 \cdot 94+1 \cdot 45$ \\
\hline Difference & $3,706 \pm 1,563$ & $3,221 \pm 547$ & $33 \cdot 7 \div 9 \cdot 7$ & $214.4 \pm 72.9$ & $0.77 \pm 0.75$ & $1 \cdot 60 \pm 0.74$ & $2 \cdot 43 \pm 1 \cdot 27$ & $27 \cdot 3 \pm 12 \cdot 0$ & & \\
\hline Significance & $\mathrm{P}<0.05$ & $P<0.001$ & $P .0 .01$ & $P<0.01$ & N.S. & $\mathrm{P}<0.05$ & N.S. & $P<0.05$ & N.S. & N.S \\
\hline
\end{tabular}


increase in plasma insulin both in the fasting specimen and in response to the glucose load (Fig. 2).

This effect was further investigated after the one-year trial period in five patients who had been treated for 13 to 16 months, and it was then found that there was no significant difference in plasma insulin concentrations at that time as compared with the results at the start of treatment. This aspect of insulin response requires further investigation. Sheldon et al. (1966) showed that there was an improvement in plasma insulin response as an early effect of acetohexamide treatment but that this receded rapidly after one to two months. Glibenclamide induced a much more prolonged improvement in plasma insulin response to glucose in diabetic patients.

The significant rises in plasma insulin were not paralleled by as great an improvement in glucose tolerance. It has been pointed out by Chu et al. (1968) that there is no evidence to suggest that chlorpropamide had increased insulin secretion independently of usual physiological stimuli. In contrast there is no doubt that the fasting plasma insulin levels on glibenclamide were significantly greater than before treatment, and this must be due to the drug. It appears to have different actions from the other members of the sulphonylurea group in that increased plasma insulin levels are maintained over a long period of time. There was a significant fall in plasma cholesterol in the whole group. Schrade et al. (1963) suggested that the level of plasma cholesterol reflected the degree of diabetic control. With their criteria glibenclamide has improved control in our patients.
From this study it is suggested that the initial dose of glibenclamide should be a single tablet of $5 \mathrm{mg}$. daily, and this can be rapidly increased to $15 \mathrm{mg}$. daily to attain control. Most patients will respond adequately at this dosage if a good response is going to be obtained. Higher dosages of up to $35 \mathrm{mg}$. daily produced no improvement over the $15-\mathrm{mg}$. dose.

We are grateful for the support of Dr. W. G. Oakley, physician-in-charge of the diabetic department, King's College Hospital. The tablets of Daonil were provided by Hoechst Pharmaceuticals, a division of Hoechst U.K. Ltd. We acknowledge the careful technical assistance of $\mathrm{Mr}$. A. C. Wise in the insulin radioimmunoassays.

\section{REFERENCES}

Aumüller, W., et al. (1966). Arzneimittel-Forschung, 16, 1640.

Chu, P. C., Conway, M. J., Krouse, H. A., and Goodner, C. J. (1968) Annals of Internal Medicine, 68, 757.

Dole, V. P. (1956). Fournal of Clinical Investigation, 35, 150.

Duncan, L. J. P., and Baird, J. D. (1960). Pharmacological Reviews, 12, 91 .

Fitzgerald, M. G., Gaddie, R., Malins, J. M., and O’Sullivan, J. (1962). Diabetes, 11, 40.

Hales, C. N., and Randle, P. J. (1963). Biochemical fournal, 88, 137.

Hales, C. N., and Randle, P. J. (1963). Biochemical fournal,
Hugget, A. S., and Nixon, D. A. (1957). Lancet, 2, 368. ller, R., Bauer. C., Schröder, R., and Saito, S. (1969). Hormone and Metabolic Research, Suppl. to vol. 1, p. 88.

Schrade, W., Boehle, E., Biegler, R., and Harmuth, E. (1963). Lancet, $1,285$.

Seltzer, H. S., Allen, E. W., Herron, A. L., jun., and Brennan, M. T. (1967). Fournal of Clinical Investigation, 46, 323.

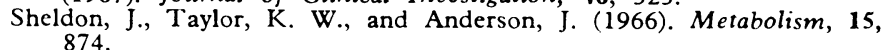

\section{Glibenclamide Therapy in Diabetes Mellitus}

S. K. BHATIA, ${ }^{*}$ M.B., B.S., M.R.C.P.ED. ; D. R. HADDEN, $\nmid$ M.D., M.R.C.P.ED. ; D. A. D. MONTGOMERY, $\dagger$ M.D., F.R.C.P.

\section{J. A. W'EAVER, $†$ M.D., M.R.C.P.}

British Medical fournal, 1970, 2, 570-572

$S^{u}$ ummary: In an initial trial of glibenclamide in the treatment of maturity onset diabetes mellitus 28 patients were treated for up to one year and no toxic effects or side-effects were encountered. The hypoglycaemic potency of this drug is such that $5 \mathrm{mg}$. of glibenclamide corresponds to about $1,500 \mathrm{mg}$. of tolbutamide and $375 \mathrm{mg}$. of chlorpropamide.

\section{Introduction}

The place of oral sulphonylurea drugs in the treatment of maturity onset diabetes mellitus has been well established for over a decade. During this period several modifications to the chemical structure of this group of substances have been introduced, resulting in drugs with different potency, duration of action, and toxicity. The chief experience of most diabetic clinics has been with tolbutamide (biological half-life 5.6 hours, dose 1 to $3 \mathrm{~g}$.) and chlorpropamide (biological halflife 35 hours, dose 0.1 to $0.5 \mathrm{~g}$.) (Hadden and Weaver, 1968).

* Research Fellow.

t Consultant Physician.

Sir George E. Clark Metabolic Unit, Royal Victoria Hospital, Belfast, BT12 6BA.
These compounds have a basic formula for effective hypoglycaemic action: $\mathrm{R}_{1}-\mathrm{SO}_{2 .} \mathrm{NH}$.CO.NH- $\mathrm{R}_{2}$. The search for improvement in this family of drugs has shown that insertion of analkylene chain into the $R_{1}$ group increased potency. considerably, and substitution of the $R_{2}$ radical with a cyclohexyl group was also beneficial. The most potent compound discovered, which also had a suitable duration of hypoglycaemic effect and a low acute toxicity in animal experiments, comparable to that of tolbutamide, was $\mathrm{N}$ - 4 - $[\beta$ - (5 - chloro - 2 - methoxybenzamido $)$ - ethyl $]$ phenylsulphonyl-N-cyclophexylurea, or glibenclamide (Daonil) (Weber et al., 1969) (Fig. 1).

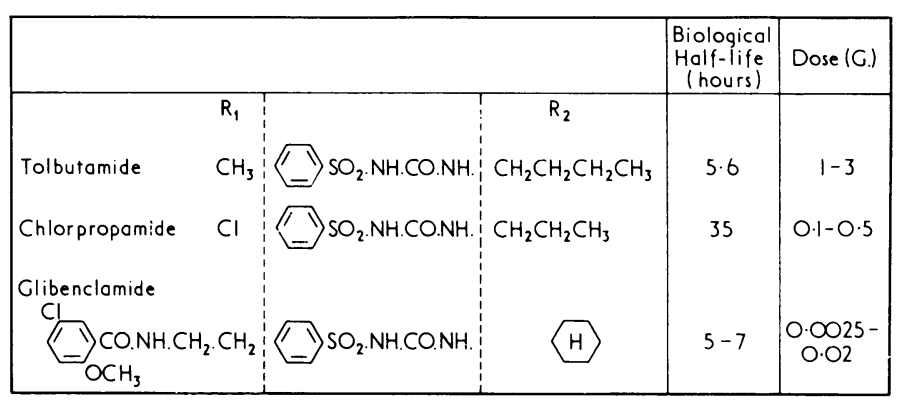

